\title{
Xenoestrogenic activity in blood of European and Inuit populations
} Eva C Bonefeld-Jorgensen ${ }^{* 1}$, Philip S Hjelmborg ${ }^{1}$, Thayaline S Reinert ${ }^{1}$, Birgitte S Andersen ${ }^{1}$, Vladimir Lesovoy ${ }^{2}$, Christian H Lindh ${ }^{3}$, Lars Hagmar ${ }^{3}$, Aleksander Giwercman ${ }^{4}$, Mogens Erlandsen ${ }^{5}$, Gian-Carlo Manicardi' Marcello Spanò ${ }^{7}$, Gunnar Toft ${ }^{8}$ and Jens Peter Bonde ${ }^{8}$

\author{
Address: ${ }^{1}$ Unit of Cellular and Molecular Toxicology, Department of Environmental and Occupational Medicine, Institute of Public Health, Vennelyst \\ Boulevard 6, Build. 1260, University of Aarhus, DK-8000 Aarhus, Denmark, ${ }^{2}$ Regional Clynical Center of Urology and Nephrology, Kharkiv, Ukraine, \\ ${ }^{3}$ Department of Occupational and Environmental Medicine, University Hospital, SE-22185 Lund, Sweden, ${ }^{4}$ Scanian Fertility Centre, Malmö \\ University Hospital, SE-20502 Malmö, Sweden, 5 Department of Biostatistics, Institute of Public Health, University of Aarhus, Vennelyst Boulevard 6 , \\ Build. 1260, DK-8000 Aarhus, Denmark, 'Laboratory of Genetics, Department of Agricultural Sciences, University of Modena and Reggio Emilia, Viale \\ Kennedy 17, I-42100 Reggio Emilia, Italy, ${ }^{7}$ Section of Toxicology and Biomedical Sciences, BIOTEC-MED, ENEA Casaccia, Via Anguillarese 301 , I- \\ 00060 Rome, Italy and ${ }^{8}$ Department of Occupational Medicine, Aarhus University Hospital, Noerrebrogade 44, Build.2C, DK-8000 Aarhus, Denmark \\ Email: Eva C Bonefeld-Jorgensen* - ebj@mil.au.dk; Philip S Hjelmborg - phj@mil.au.dk; Thayaline S Reinert - line_job1@hotmail.com; \\ Birgitte S Andersen - bsa@mil.au.dk; Vladimir Lesovoy - dimusic@ic.kharkov.ua; Christian H Lindh - Christian.Lindh@med.lu.se; \\ Lars Hagmar - lars.hagmar@ymed.lu.se; Aleksander Giwercman - aleksander.giwercman@kir.mas.lu.se; \\ Mogens Erlandsen - mogens@biostat.au.dk; Gian-Carlo Manicardi - manicardi.giancarlo@unimo.it; \\ Marcello Spanò - spanomtc@mail.casaccia.enea.it; Gunnar Toft - gutof@as.aaa.dk; Jens Peter Bonde - jpbon@as.aaa.dk \\ * Corresponding author
}

Published: 05 May 2006

Environmental Health: A Global Access Science Source 2006, 5:12 doi:10.1 I86/1476-069X-5-12
Received: 16 November 2005

Accepted: 05 May 2006

This article is available from: http://www.ehjournal.net/content/5/I/I2

(C) 2006 Bonefeld-Jorgensen et al; licensee BioMed Central Ltd.

This is an Open Access article distributed under the terms of the Creative Commons Attribution License (http://creativecommons.org/licenses/by/2.0), which permits unrestricted use, distribution, and reproduction in any medium, provided the original work is properly cited.

\begin{abstract}
Background: Human exposure to persistent organic pollutants (POPs) is ubiquitous and found in all individuals. Studies have documented endocrine disrupting effects and impact on reproduction. The aim of the present study was to compare the level of xenoestrogenic activity in serum of groups with varying POP exposure, and to evaluate correlations to the POP biomarkers, 2,2',4,4',5,5'-hexachlorobiphenyl (CB-I53) and I, I-dichloro-2,2-bis ( $p$-chlorophenyl)-ethylene ( $p, p^{\prime}$-DDE).

Methods: The study included 358 men: Greenlandic Inuit's, Swedish fishermen, and Warsaw (Poland) and Kharkiv (Ukraine) inhabitants. Xenoestrogenicity of serum extracts alone (XER) and XER competitive (XERcomp) effect on I7 $\beta$-estradiol induced estrogen receptor (ER) transactivity were assessed in the hormone free, lipophilic serum fraction containing the POPs using the MVLN human breast cancer cell line.

Results: No agonistic XER activity was exhibited for Inuit serum samples, while $12-24 \%$ of the European samples had detectable agonistic XER activity. On the contrary, $71 \%$ of Inuit serum samples antagonized XERcomp compared to $7-30 \%$ in the other regions. XER and XERcomp were not or weakly correlated to the two POP markers. XER activity of Inuit samples was negatively associated to levels of CB-I53 and p, $p^{\prime}-\mathrm{DDE}$. For the Warsaw group a positive and negative correlation between $X E R$ and $p, p^{\prime}-D D E$ and estradiol equivalence level and $C B-153$ levels was found.

Conclusion: No strong consistent association between xenoestrogenic net activity and the two POP markers was found. The results showed that the selected POP markers alone can not predict the integrated xenoestrogenic serum activity. Correlations to the POP markers were found at the extreme edge; the Inuit's and Warsaw study groups eliciting high frequency of samples with ER antagonistic and agonistic activity, respectively. We suggest that the variation in xenoestrogenic serum activity reflects differences in POP exposure mixture, genetic factors and/or life style factors.
\end{abstract}




\section{Introduction}

Human exposure to environmental contaminants is ubiquitous and affects also individuals living far away from the source of contaminants such as industries, combustion and waste disposal sites. Mainly caused by dietary exposure and due to their resistance to environmental and biotic degradation persistent organochlorine pollutants (POPs), e.g. chlorinated pesticides and polychlorinated biphenyls (PCBs), accumulate in body fat tissues of humans and animals. Many POPs can mimic hormone activities and are, therefore, potential endocrine disrupters (EDs) suspected to increase the risk of cancer, birth defects, reproductive and neuro-immune disorders [1-3]. To date, no clear-cut evidence for adverse endocrinerelated human health effects of POPs have been obtained at the individual or population level. However, data from studies on wild-life species, laboratory animals and biomarker effects in vitro have strengthened the need for further research to address the concern.

The sex steroid receptors such as the estrogen receptor $\alpha$ $(\mathrm{ER} \alpha)$ and $\mathrm{ER} \beta$ and the androgen receptor (AR) belongs to the nuclear receptor family and are generally liganddependent transcription factors [4-6]. Their genomic mediated pathway include steps as binding of ligand to receptor, translocation into nucleus and binding of the receptor-ligand complex to a specific DNA response element causing a gene response. Androgens and estrogens are not male or female hormones only. Both hormones are important in both sexes and an absolute necessity for reproductive development including male fertility [7]. The steroid androgen hormones, testosterone and dihydrotestosterone, are necessary for the normal male phenotype and the presence of ER $\alpha$ and ER $\beta$ in human foetal testis and epididymis cells indicates that estrogens play a physiological role in regulations of spermatogenesis in mammals [8-10].

There is extensive data of in vitro mechanism based models on endocrine-related POPs effects on sex hormonal systems [11-14]. Although much less potent compared to $17 \beta$-estradiol (E2) the three PCB congeners CB-138, CB153 and CB-180, comprising up to $50 \%$ of the bio-accumulated sum of PCBs, elicit a receptor mediated antiestrogen and/or antiandrogen in vitro activity [15], and similarly some hydroxylated PCBs exert low potency estrogenic and/or antiestrogenic effects [16,17]. Generally PCBs do not bind to the sex hormone binding globulin (SHBG) or at very low affinity [18], which may cause a higher bio-availability of the compounds. Animal studies have indicated that prenatal exposure to POPs as PCBs, dioxins and $p, p^{\prime}$-DDE is associated with reduced male fertility [19-24], whereas the effect of POPs on human fertility is still controversial [25,26], and therefore an integrated risk assessment of EDs is needed [27]. In vitro studies of xenoestrogen mixtures present at or below their no-observed-effect concentration (NOEC) or sub-NOEC was demonstrated to cause a dramatic additive enhancement of hormone actions [28,29]. Rather than monitoring the level of identified xenoestrogens, the integrated biological activity was used to estimate the xenobiotic burden of serum samples using [17,30-32].

The present study was a part of the EU supported research project Inuendo [33]. The specific aim of the present study was to compare xenoestrogenic activities across Inuit's and European regions, and to evaluate whether the serum levels of the POP biomarkers, CB-153 and $p, p^{\prime}$-DDE, were associated to the actual xenoestrogenic net activity in blood.

\section{Subjects and methods \\ 2.I Study population and collection of blood samples}

Based on earlier reports of POP body burdens four populations were included in the Inuendo study [33] for a cross-sectional fertility study representing a wide range of POP burdens. For the present study the aim was to recruit 300 male spouses to pregnant women in Greenland, Warsaw (Poland) and Kharkiv (Ukraine), and a subgroup (n $=100$ ) of an already established cohort of fishermen from Sweden was also included in the study [25]. A general criterion for eligibility was that the participants had to be born in the country of study and at least 18 years of age. Serum samples were randomly selected from the main Inuendo study groups, and the intension was to analyse serum samples including high and low POP exposure within each study group. However, because of the limit in project timing and in some cases too little blood was collected for the analysis, serum samples were randomly selected before POP determination, and fewer serum samples were analyzed. Males were recruited during 20022004 in Greenland ( $\mathrm{n}=72$; Sisimiut, West Coast $\mathrm{n}=50$, and Tasiilaq, East Coast $\mathrm{n}=22$ ), in Warsaw, Poland $(\mathrm{n}=$ 99) and in Kharkiv, Ukraine $(n=88)$ [25]. Earlier studies have reported high POP levels in Greenlandic Inuit's and differences in levels between habitants of the East and West Coast of Greenland [34,35]. However to keep similar power in the four study groups the statistical evaluation was carried out on the combined Greenlandic data only.

Information about demographic and lifestyle factors as age, body mass index (BMI), intake of seafood, coffee, smoking habits, and alcohol consumption was collected by interviews (Table 1) [25,35]. Venous blood samples were collected into $10 \mathrm{ml}$ vacuum tubes and after centrifugation the serum was transferred to Nunc tubes and stored at $-80^{\circ} \mathrm{C}$ for later analysis [35]. The study was approved by the local ethical committees representing all 
Table I: Demographic and life style characteristics of men in the study groups

\begin{tabular}{|c|c|c|c|c|c|c|}
\hline & & Greenland $n=72$ & Warsaw $n=98$ & Sweden $n=100$ & Kharkiv $n=88$ & All $n=358$ \\
\hline Age & median & $30(70)$ & $30(97)$ & $47(96)$ & $25(85)$ & 31 (348) \\
\hline years & $\min -\max$ & $18-46$ & $24-46$ & $24-68$ & $16-45$ & $16-68$ \\
\hline BMI & median & $26(72)$ & $25(96)$ & $26(99)$ & $24(86)$ & $25(353)$ \\
\hline $\mathrm{Kg} / \mathrm{m}^{2}$ & $\min -\max$ & $12-38$ & $19-38$ & $22-37$ & $19-36$ & $12-38$ \\
\hline Alcohol & median & $2.0(36)$ & $3.5(86)$ & n.a & $2.5(66)$ & $3.0(188)$ \\
\hline drink/week & $\min -\max$ & $0-2 I$ & $0-30$ & & $0.2-15$ & $0-30$ \\
\hline Smoking ever & $\%$ & $89(7 I)$ & $50(97)$ & $60(98)$ & $82(87)$ & $68(353)$ \\
\hline Seafood & median & I.5 (68) & $1.0(89)$ & n.a & $4.0(86)$ & $2.0(243)$ \\
\hline days/week & $\min -\max$ & $0-9.0$ & $0-9.0$ & & $1.0-9.0$ & $0-9.0$ \\
\hline Coffee & median & $3.0(62)$ & $2.0(83)$ & n.a & $2.0(37)$ & $2.0(182)$ \\
\hline cups/day & $\min -\max$ & $0-20$ & $0-6.0$ & & $0.5-7.0$ & $0-20$ \\
\hline Total testosterone & median & $15(36)$ & $13(76)$ & $12(99)$ & $18(88)$ & 14 (299) \\
\hline $\mathrm{nmol} / \mathrm{l}$ & $\min -\max$ & $3.2-25$ & $6.5-23$ & $4.2-28$ & $8.4-32$ & $3.2-32$ \\
\hline Estradiol & median & $59(35)$ & $71(76)$ & $67(99)$ & $78(88)$ & $70(298)$ \\
\hline $\mathrm{nmol} / \mathrm{l}$ & $\min -\max$ & $31-89$ & $45-297$ & $25-154$ & $33-144$ & $25-297$ \\
\hline
\end{tabular}

The values in the bracket are the numbers of individuals with data for the specific demographic and life style characteristics.

participating populations and all subjects signed an informed consent.

\subsection{Determination of CB-I53 and p,p'-DDE in serum}

Serum concentrations of CB-153 and $p, p^{\prime}$-DDE were determined using solid phase extraction (SPE) and on-column degradation of lipids followed by analysis with gas chromatography mass spectrometry as described [35]. CB-153 and $p, p^{\prime}$-DDE levels were adjusted for serum lipids. Levels of detection, coefficients of variation and participation in quality control programs have been described in detail elsewhere $[35,36]$.

\subsection{SPE-HPLC fractionation of the serum samples}

To obtain the serum fraction containing the actual mixture of bio-accumulated POPs a solid phase extraction (SPE) followed by high-performance liquid chromatography (HPLC) fractionation was performed on $3.6 \mathrm{ml}$ serum [37]. Similar to the described methods [17,30,38] the POPs were extracted from the serum by SPE separation on a Spherisorb Si 60 analytical column $(250 \times 4.6 \mathrm{~mm}$ i.d., $5 \mu \mathrm{m}$ particle size, Waters, Milford, MA, USA). This is a normal phase column and thus the separation is based on lipophilicity. This crude serum extract was then further processed using HPLC in order to separate the POPs from the endogenous hormones. The first fraction (F1: 0.00$5.30 \mathrm{~min}$, protected from light in brown tubes) was set up to include most POPs while leaving out endogenous hormones by testing 18 lipophilic chemicals including PCBs, pesticides, akylphenols, bisphenol A, 6 endogenous hor- mones (estrogens and androgens), and 1 oral contraceptive on the HPLC system using retension times as discriminating factor. This F1 SPE-HPLC fraction was evaporated to near dryness and frozen for later ER mediated chemical activated luciferase gene expression (ERCALUX) analysis. ER-CALUX analyses of the HPLC fractions F1, F2.1 (5.30 - $12.0 \mathrm{~min})$ and F2.2 (12.00 - 14.5 $\min$ ) verified that the endogenous hormones were separated from F1 but found in F2.1 and F2.2. Moreover, comparison of SPE-HPLC F1 extracts obtained by our system with F1 extracts obtained from another laboratory (Institute of Public Health, University of Southern Denmark) elicited same responses in the ER-CALUX analyses [37].

Two pools of blood bank serum (Aarhus Sygehus, Denmark), one male (KHM) and one female (KHF), were distributed into tubes with $3.6 \mathrm{ml}$ and stored at $-80^{\circ} \mathrm{C}$. One sample from each sex was weekly processed by the SPEHPLC method in parallel with the project samples serving as serum controls for the cleanup procedure. The day to day inter assay coefficient of variation (CV) of the SPEHPLC + ER-CALUX analyses of these control blood samples were $\leq 13 \%$.

\subsection{Dissolving the SPE-HPLC samples}

The SPE-HPLC extracts samples (project samples and controls) were thawed and protected from light during handling. Sample solvent, $20 \mu \mathrm{l}$ EtOH: $\mathrm{H}_{2} \mathrm{O}: \mathrm{DMSO}$ (50:40:10), was added to each sample tube and the samples were placed in an Eppendorf Thermomixer Comfort 
at $550 \mathrm{rpm}$ and $37^{\circ} \mathrm{C}$ for 15 minutes. Then $200 \mu$ growth media $[0.5 \%$ Dextran-Charcoal treated foetal calf serum (DC-FCS, Hyclone, Bie \& Berntsen, Aarhus, DK) in phenol red-free Dulbecco's Modified Eagle's Medium (DMEM) (Gibco, Invitrogen, Taastrup, DK) supplemented with 4 mM glutamine (Sigma-Aldrich, Vallensbaek Strand, DK) and $1.28 \mathrm{mg} / \mathrm{ml}$ garamycin (Schering-Plough, Dassel, Germany)] was added to each sample and the shaking at $550 \mathrm{rpm}$ and $37^{\circ} \mathrm{C}$ was continued for another $15 \mathrm{~min}$ utes. Then each sample was transferred to two new test tubes (100 $\mu \mathrm{l} /$ tube) each containing $400 \mu \mathrm{l}$ growth media with or without the normal ER ligand E2, respectively, and used for ER-CALUX determinations.

\subsection{ER-CALUX assay}

The stable transfected MVLN human breast cancer cell line (kindly provided by M. Pons, France) carrying the endogenous ER $\alpha$ and ER $\beta$ genes, and the introduced estrogenresponse-element (ERE)-luciferase reporter vector [39] was used for determination of ER-CALUX activities as described [40]. The measured luciferase data was corrected to cell protein (internal control), and expressed in relative light units per microgram protein (RLUs/ $\mu$ g protein). All controls and SPE-HPLC F1 serum extracts (100 $\mu \mathrm{l} /$ well) were analysed in triplicate. If one of the triplicate values deviated more than $30 \%$ the mean was calculated from two wells only. An E2 dose-response control in the concentration range from $0.05 \mathrm{pM}$ to $500 \mathrm{pM}$ (solvent $96 \%$ ethanol $=0.1 \%$ ) was performed in parallel each analysis day as described [14,40]. The maximal effective concentration $\left(\mathrm{EC}_{100}\right)$, the half maximum effective concentration $\left(\mathrm{EC}_{50}\right)$, and $\mathrm{EC}_{40}$ of $\mathrm{E} 2$ was calculated to $150 \mathrm{pM}, 33 \mathrm{pM}$ and $25 \mathrm{pM}$, respectively, by fitting the dose-response data into Chapman, 4 parameter sigmoid equation curve using Sigma Plot 8.0 (SPSS, Chicago, IL, USA). The E2-EC ${ }_{100}$ and the $\mathrm{E} 2-\mathrm{EC}_{40}$ were used as parallel positive controls on each plate in each assay. Xenoestrogenic activity (XER) was determined by exposure of the cells to serum extracts alone and XERcomp activity upon co-exposure of the cells to serum extract +25 pM E2 $\left(\mathrm{EC}_{40}\right)$. The solvent controls of XER and XERcomp activity were sample solvent only and the sample solvent plus 25 pM E2 $\left(E_{40}\right)$, respectively (see 2.3.1 for handling procedure), and for XER and XERcomp activity calculation the respective solvent controls (RLU/ $\mu$ g protein) were set to 1 . Finally, the data was given as activity per $\mathrm{ml}$ serum and the values of the solvent controls were $3.13 \mathrm{RLU} / \mathrm{ml}$ serum.

The E2 equivalence (XER-EEQ) value of the agonistic XER activities was obtained by interpolation of data onto the Chapman 4 parameter sigmoid curve using the doseresponse E2 Sigma Plot curve. Both the average ERCALUX inter-CV of the solvent controls and intra-individual CV for serum sample extracts were below 5\%.
No cell toxicity on MVLN determined by CellTiter 96 Cell Proliferation assay from Promega (Madison WI, US) [40] was observed after exposure to SPE-HPLC extracts.

\subsection{Statistical analysis}

The comparisons of means between XER, XERcomp and XER-EEQ were performed by the Oneway-ANOVA test. When ANOVA indicated significant group difference complementary multiple comparison ad hoc tests were used. The test for homogeneity of variance was performed with Levene's test. The least significant difference (LSD) pair wise multiple comparison test was used for the variables with equal variance ( $\mathrm{p} \geq 0.05)$ and Dunnett's T3 test was used for the variables with an unequal variance $(\mathrm{p} \leq 0.05)$.

The association in each study group between POP marker and xenoestrogen activity was evaluated by means of Spearman's rank correlation. The overall association between the POP marker and xenoestrogen activity across the study groups (combined data) were evaluated by comparing the regression lines for each study group (multiple regression analysis).

Our hypothesis is that a potential determinant of POP bioaccumulation might also be a potential determinant for serum xenoestrogenic activity. As known from the literatures and also from an assessment of the total Inuendo study populations $[25,35]$ age and seafood are such determinants. Moreover, lifestyle characteristics (Table 1) were evaluated as potential determinants of XER and XERcomp levels of combined data and the separate study groups. Using multivariate linear regression analyses, assessing the impact of the POP biomarkers on XER and XERcomp, the impact of potential confounders were evaluated by entering blocks of variables together with either CB-153 or $p, p^{\prime}$-DDE as follows: In the first step age and seafood intake (continuous variables) were included in the model, and in the second step additionally smoking status (smoked ever yes/no), BMI, and coffee intake was included as continuous variables. Alcohol consumption was only recorded for limited number $(n=188$, see Table 1) of subject and not for the Swedish study group. Therefore, the second step was carried out with and without alcohol consumption in the potential confounder model, which did not change the overall pattern of non-adjusted to adjusted data. Due to many missing values on the potential confounders (Table 1) the number of available observations in the confounder analyses are much smaller than in the unadjusted analysis on the full dataset (full dataset (XER, XERcomp and POP markers) $\mathrm{N}=348$; first step of confounders: $N=231$; second step: $N=172$ ). A reduction of the number of observations with 50\% might introduce serious selection problems, and hence the confounder analyses might lack greater validity. 
Table 2: Xenoestrogenic serum activities, estradiol equivalents and lipid adjusted CB-153 and p,p'-DDE in serum of the study groups

\begin{tabular}{|c|c|c|c|c|c|c|c|}
\hline & & Greenland & Warsaw & Sweden & Kharkiv & ALL*4 & $\begin{array}{c}\text { All study group } \\
\text { data }^{* 5}\end{array}$ \\
\hline \multirow[t]{7}{*}{ XER*'RLU/ml serum } & $\mathrm{N}$ & 72 & 98 & 100 & 88 & 358 & 0.003 \\
\hline & Median & 2.89 & 3.09 & 3.04 & 3.15 & 3.05 & \\
\hline & Mean & 2.92 & 3.30 & 3.22 & 3.17 & 3.17 & \\
\hline & Min & 1.0 & 2.4 & 2.4 & 1.0 & 1.1 & \\
\hline & Max & 6.0 & 6.5 & 12 & 8.0 & 12 & \\
\hline & $\%$ agonist & 1 & 21 & 12 & 14 & - & \\
\hline & $\%$ antagonist & 35 & 5 & 12 & 17 & - & \\
\hline \multirow[t]{5}{*}{ XER-EEQ pg/g lipid*2 } & $\mathrm{N}$ & $1 *$ & 21 & 10 & 11 & 43 & 0.63 \\
\hline & Median & - & 103 & $76 \varphi$ & 139 & 114 & \\
\hline & Mean & - & 166 & 161 & 179 & $|7|$ & \\
\hline & Min & - & 44 & 50 & 80 & 44 & \\
\hline & Max & - & 516 & 364 & 580 & 580 & \\
\hline \multirow{7}{*}{ XER comp ${ }^{* 3} \mathrm{RLU} / \mathrm{ml}$ serum } & $\mathrm{N}$ & 72 & 94 & 94 & 88 & 348 & $<0.001$ \\
\hline & Median & 2.65 & 2.96 & 2.90 & 2.88 & 2.86 & \\
\hline & Mean & 2.69 & 3.29 & 2.89 & 2.87 & 2.95 & \\
\hline & Min & 2.0 & 1.8 & 1.0 & 1.1 & 1.0 & \\
\hline & Max & 3.8 & 7.0 & 6.8 & 4.5 & 7.0 & \\
\hline & $\%$ add/syn & 1 & 13 & 3 & 1 & - & \\
\hline & $\%$ antagonist & 71 & 7 & 19 & 30 & - & \\
\hline \multirow[t]{4}{*}{ CB-153 ng/g lipid } & $\mathrm{N}$ & 74 & 100 & 98 & 82 & 354 & $<0.001$ \\
\hline & Median & 220 & 16 & 210 & 47 & 79 & \\
\hline & Min & 5.1 & 33 & 4.1 & 5.5 & 3.3 & \\
\hline & Max & 5500 & 130 & 1500 & 200 & 5500 & \\
\hline \multirow[t]{4}{*}{ DDE ng/g lipid } & $N$ & 74 & 100 & 98 & 82 & 354 & $<0.001$ \\
\hline & Median & 630 & 570 & 240 & 880 & 560 & \\
\hline & Min & 66 & 240 & 55 & 324 & 55 & \\
\hline & $\operatorname{Max}$ & 13000 & 2100 & 2300 & 12000 & 13000 & \\
\hline
\end{tabular}

In the independent assays significant differences between the triple serum extract determinations and their respective solvent controls (\% agonists/ additive/synergistic) and \% antagonists, were tested by the Student's t-test (Microsoft Office Excel, significance level $p=0.05$ ). $* 1$ : XER:

Xenoestrogenic agonistic or antagonistic activity of serum extract alone: the solvent control $=3.13 \mathrm{RLU} / \mathrm{ml}$ serum. \% agonistic and \% antagonistic indicates the \% of samples eliciting a significantly increase or decrease in XER activity compared to solvent control, which was set to I. $* 2$ : XERestradiol equivalence (XER-EEQ) of the samples eliciting significantly agonistic activity; data calculated by interpolation to the E2 dose response curve using the sigma plot program. $\vee$ : One Swedish sample was too high to calculate the XER-EEQ. * : One serum sample from Greenland only had an agonistic action, thus no XER-EEQ value is given. *3: XERcomp; XER competitive activity of serum extract +25 pM I7 $\beta$-estradiol (E2-EC 40$)$; $\%$ add/syn: additive/synergistic and \% antagonistic indicates the \% of samples responding with a further increase or a decrease of the $\mathrm{E}_{2}-\mathrm{EC}_{40}$

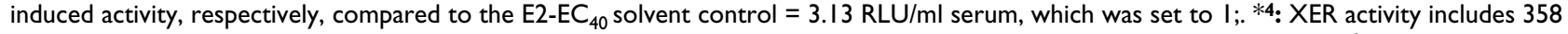
samples, however, only 348 of theses samples were applied to the XERcomp analyses. All of the samples had CB-I53 and $p, p^{\prime}-D D E$ determined. $* 5$ : One-way ANOVA ( $p$ value) evaluation of the combined study group data except for XER-EEQ including only the European groups. In transformed data was used.

The XER and XERcomp activities were determined in protein free serum extracts free of endogenous estrogens and testosterone. As a method verification Spearman's rank correlation analyses of XER and XERcomp against determined blood levels of estradiol and testosterone (total and free) [41] were performed on the combined study group data.

Normal distribution was assessed by Q-Q plots. To improve normality and homogeneity of variance, the XER and XERcomp activities as well as lipid adjusted CB-153 (lip-CB-153) and $p, p^{\prime}$-DDE (lipDDE) were natural logarithmic transformed and the statistical analyses were performed on the ln-transformed data. The POP variables were treated as continuous variables. The statistical analy- sis was performed in SPSS 10.0 (SPSS Inc, Chicago, IL) with the significance level $\mathrm{p} \leq 0.05$.

\section{Results}

\section{I Basic characteristics, CB- I53, p,p'-DDE and} xenoestrogenic serum levels

The distribution of demographic and lifestyle factors (Table 1) and serum CB-153 and p,p'-DDE median levels (Table 2) that may potentially influence the ER-mediated activities of the 358 adult males in this study were similar with that obtained for the total Inuendo study population $[25,35]$. Correlation between serum concentration of CB153 and $p, p$-DDE was found with higher correlations in Greenland $\left(r_{s}=0.94\right)$ and Sweden $\left(r_{s}=0.75\right)$, while relatively lower correlation was observed for the study group of Kharkiv $\left(r_{s}=0.45\right)$ and Warsaw $\left(r_{s}=0.28\right)$. 
The Greenlandic serum extracts elicited predominantly antagonistic effect on XER (35\%) and XERcomp (71\%), whereas the European samples elicited relatively higher frequency of XER agonistic activity (12-21\%) of which the Warsaw samples had the highest mean of XER/XERcomp (Table 2 and Figure 1).

Oneway ANOVA analyses showed significant differences between the study groups (Table 2). Multiple comparisons of means showed that Inuit XER activities significantly differed from each of the three European study groups ( $\mathrm{p} \leq 0.03)$; whereas the XER activity and XER-EEQ of the European study groups did not mutually differ. Only one sample from Greenland elicited XER agonistic activity and thus no XER-EEQ data was given for the Inuit's. The XERcomp activity of the Warsaw group differed from all other study groups $(p \leq 0.004)$.

\subsection{Associations between xenoestrogenic activity and CB- 153 and $\mathrm{p}, \mathrm{p}^{\prime}-\mathrm{DDE}$}

XER activity for Inuit's showed an inverse correlation to the $p, p^{\prime}$-DDE levels $\left(r_{s}=-0.29 ; p=0.02\right)$ and borderline inverse to CB-153 $\left(r_{s}=-0.22 ; p=0.07\right)$. For the Warsaw study group the XER activity showed a significant positive correlation to the $p, p^{\prime}$-DDE data $\left(r_{s}=0.21 ; p=0.04\right)$, and for XER-EEQ a significant negative correlation to CB-153 $\left(r_{s}=-0.45 ; p=0.04\right)$ was found (See Additional file 1 : Spearman's correlation analyses between xenoestrogenic serum activities and the level of CB-153 and p,p'-DDE). No further correlations between XER, XERcomp or XEREEQ and any of the two POP markers were found. Adjustment for the potential confounders in the multivariate regression model did not give any different results for the impact of the POP biomarkers on XER and XERcomp as compared with the unadjusted models, neither for the combined data or each study group (data not shown).

\subsection{Multiple regression of xenoestrogenic activity on POP data across the study groups}

Scatter plots of XER or XERcomp against CB-153 or p, p'DDE for the four study groups are shown in Figure 2. Multiple regression analysis of both response variables (XER and XERcomp) showed homogeneity of slopes between study groups and CB-153/p, $p^{\prime}$-DDE (Table 3 ), i.e. parallel regression lines among study groups. Furthermore, a model with parallel regression lines showed significant differences between the intercepts of the study groups (Table 3). Thus the differences in XER/XERcomp between study groups found by Oneway ANOVA (Table 2) and multiple comparisons still exist after adjustment for CB153 or $p, p^{\prime}$-DDE. Finally, we note that although correlations was observed between XERs and the POP markers for the Greenlandic and Warsaw study groups (Supplement), for the combined data the associations between XER/XERcomp and CB-153/DDE, as measured by the common slopes, are very weak and not statistically significant (Table 3).

\subsection{Correlations between xenohormone activities and endogenous hormone levels}

To verify the exclusion of endogenous hormones from the SPE-HPLC- F1 serum extracts used for CALUX activity measurements, the XER, XER-EEQ and XERcomp results were evaluated for possible correlation to blood estradiol $(\mathrm{pmol} / \mathrm{L})$ and testosterone $(\mathrm{nmol} / \mathrm{L})$ (free and total) levels. No correlations were found between the serum XER/ XERcomp activities and blood sex hormone levels neither for the combined data nor for the separate study groups.

\section{Discussion}

In the present study we determined the actual xenoestrogenic net activity in serum of adult men from Greenland, Sweden, Warsaw (Poland) and Kharkiv (Ukraine), representing populations with different POP exposure patterns (Table 2) $[34,35,42,43]$. For the combined data no strong consistent correlations between serum xenoestrogenic activity and the two POP proxy markers, CB-153 and p, $p^{\prime}$ DDE, was observed. Significant correlations between marker POPs and xenoestrogenic serum activity was found for Inuit's and the Warsaw group, having the lowest and highest ratio of agonist:antagonist samples, respectively; an inverse association of XER activity to the p,p'DDE and CB-153 levels for Inuit's, and for the Warsaw group a positive and a negative association of XER to $p, p^{\prime}-$ DDE and XER-EEQ to CB-153, respectively. Because of the high inter-correlation between CB-153 and $p, p^{\prime}$-DDE for the Inuit's it can not be assessed which of the two POPs exert the main impact. However, for the Warsaw group the very low concentration of CB-153 and low inter-correlation of marker POPs indicates that $p, p$-DDE might have a positive effect on XER activity, and CB-153 an inverse impact on agonistic XER as elicited by XER-EEQ. Overall, these data might be explained by the high level of PCBs in Greenland with predominant anti-estrogenic actions $[15,17,44-46]$ and relatively high level of $p, p^{\prime}$-DDE in the Warsaw group having weak estrogenic action $[17,28,47,48]$. However, that does not explain why no correlations were observed for the Swedish and Kharkiv groups since they had a CB-153 and $p, p^{\prime}$-DDE marker profile similar to Greenland and Warsaw, respectively. Multiple regression analyses showed, that the determined differences of XER and XERcomp activity between the study groups could not be explained by the two selected POP proxy markers alone neither in combination with the measured potential confounders in the present study. However, the combined XER vs. CB-153 data showed homogeneity across the study groups, had common slopes and similar intercept $(\mathrm{p}=0.05$, Table 3 , Figure 2$)$, and assuming a common intercept a significant $(\beta=$ $0.132, p=0.01)$ negative correlation between CB-153 and 

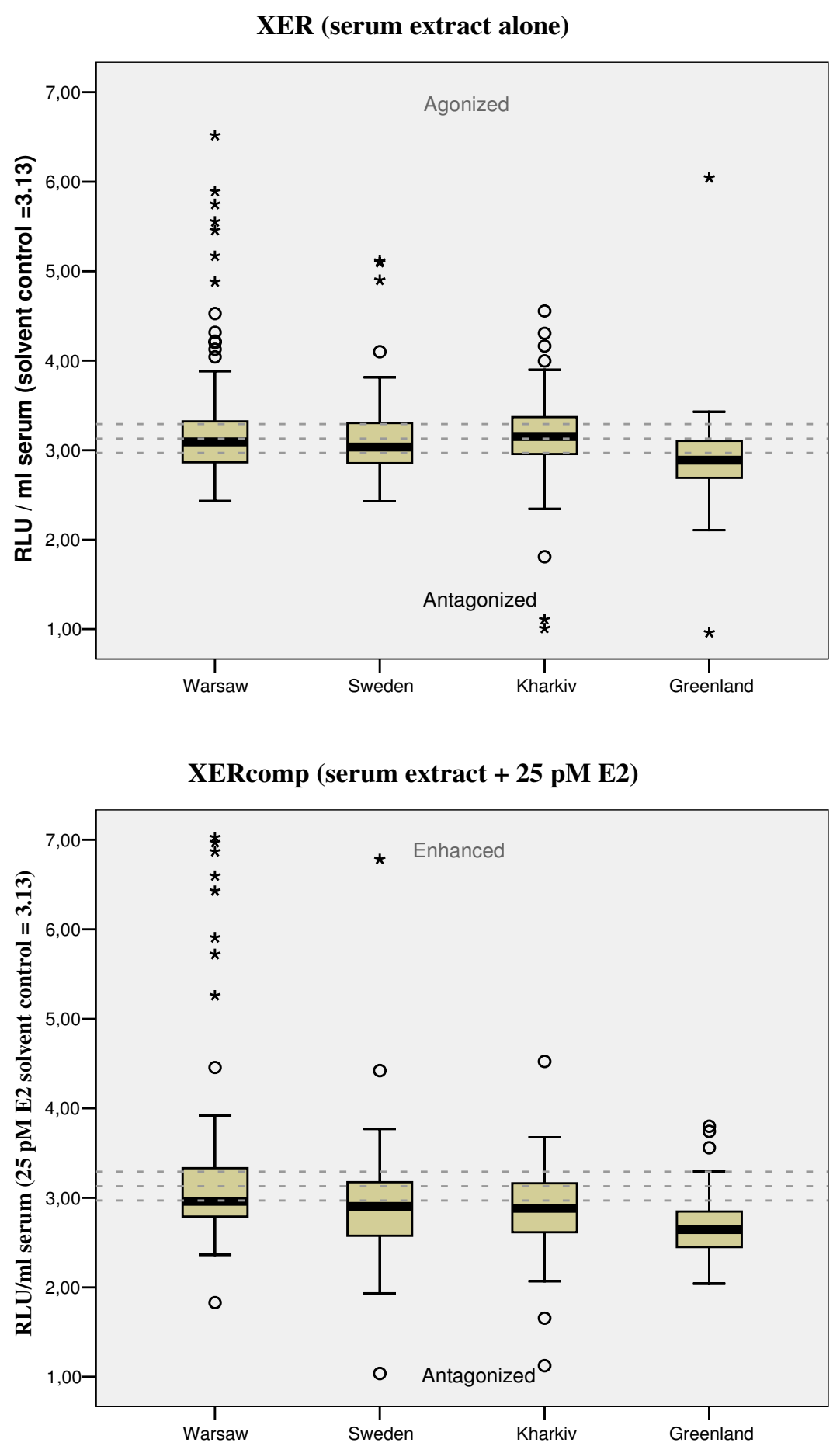

\section{Figure I}

The xenoestrogenic CALUX activity of study groups. (A) Agonistic activity of serum extracts alone (XER) and (B) competitive XER activity upon coexposure with 25 PME2 $\left(E C_{40}\right)$ (median, quartiles ( $25 \%$ and $75 \%$ ) and extreme variables). For the Swedish study group an extreme agonistic (A) RLU value of 12.02 was determined (not shown). The reference line of the respective solvent controls \pm SD $(3.13 \pm 0.16)$ are given as dotted lines. 
Table 3: Multiple regressions of the combined study group data

\begin{tabular}{lccccc}
\hline Response variable & $\begin{array}{c}\text { Exposure } \\
\text { variable }\end{array}$ & $\begin{array}{c}\text { Homogeneity of } \\
\text { slopes (p-value) }\end{array}$ & $\begin{array}{c}\text { Common slope } \\
\text { Estimate (SE) p-value }\end{array}$ & $\begin{array}{c}\text { Common intercept } \\
\text { (p-value) }\end{array}$ & $\begin{array}{c}\text { Adjusted R- square } \\
\text { XER (N = 348) }\end{array}$ \\
& CB-153 & 0.86 & $-0.01(0.01), 0.34$ & 0.05 & 0.029 \\
XERcomp (N = 338) & P, - DDE & 0.24 & $-0.03(0.02), 0.12$ & 0.005 & 0.034 \\
& CB-I53 & 0.20 & $0.01(0.02), 0.45$ & $<0.001$ & 0.087 \\
& p, - DDE & 0.15 & $-0.006(0.02), 0.71$ & $<0.001$ & 0.086 \\
\hline
\end{tabular}

Response and exposure variables are In-transformed in the analysis. Homogeneity of slopes: p-value for the test for homogeneity of slopes between study group and exposure variable. Common slope: the estimated common slope across study groups assuming no interaction. Common intercept: $\mathrm{p}$-value for the test of a common intercept across study groups assuming a common slope. Adjusted R-square assuming a common slope.

XER activity was found. Future studies might elucidate whether our observations are serendipitous.

Between the groups the XER and XERcomp activities differed significantly. The Inuit's clearly differed from the European study groups eliciting no agonistic but high frequency of samples (71\%) with antagonistic action. In contrast, the European serum samples exerted both agonistic (12 - 21\% of the samples) and antagonistic effects ( $7-30 \%$ of the samples).

The heterogeneous pattern of xenoestrogenic correlations to CB-153/p, $p$-DDE levels and also the differences in xenoestrogenic activity among the study groups might be explained by different exposure profiles e.g. : i) the estrogenic effects elicited by ER transactivity is a consequence of the combined net effects of many POPs having either ER agonistic or ER antagonistic actions; ii) the two selected POP markers do not reflect and/or represent the chemicals primarily responsible for the determined xenoestrogenic effects; iii) the combined response of the serum mixture is significant affected although the concentration of the single compounds found in human serum is lower than that needed to elicit a response of the compound on its own in an in vitro system; and finally iv) the net XER/XERcomp activities is the net response of exposure patterns, genetic background and life style factors. In summary, based on the two selected POP markers only, it is hard to predict the net xenoestrogenic impact in vivo as well as in the present ex vivo xenoestrogenic measurements.

The use of CB-153 and $p, p^{\prime}$-DDE in serum as index biomarkers of POP exposure has been supported by several previous studies [49-52]. However, it must be taken into consideration that the relative concentrations of noncoplanar and co-planar PCBs can differ between regions depending on varying exposure sources. The ratio between serum levels of CB-153 (and other non-coplanar congeners) and co-planar PCBs was higher in Canadian Inuit's than in Canadian Caucasians from the Arctic area [53], which calls for caution using CB-153 as a global exposure marker for POP as well as for xenoestrogenic serum activities. In the present study it might be expected that the ratio between non-dioxin-like, non-coplanar PCBs (e.g. CB-153) and co-planar PCB (e.g. CB-126) also is higher for the Greenlandic Inuit's compared to the three European study groups.

In vitro studies demonstrated that the combined effect of several xenoestrogens including POPs at sub-NOEC exerted an additive effect, which led to dramatic change in estrogenic in vitro activity $[28,29]$. To elucidate potential human and wildlife responses to the combined impact of accumulated xenoestrogens it remains to be demonstrated mechanistically how chemicals with antiestrogen effects can modify the response of chemicals acting estrogenic in a concerted action. It can be argued that xenoestrogenic equivalents contribute only a few percent to the endogenous hormone activity - even when possible higher bioavailability of the xenobiotics is taken into consideration. However, considering the further increase of XERcomp above the reference control (25 pM E2) we calculated (using Sigma Plot and the data of the E2 doseresponse curve) for this subgroup of men $(n=86)$ a further mean activity increase of $47 \%$ and $21 \%$ in relation to the minimum (34 pM) and mean (70 pM) endogenous estradiol level, respectively. Since the level of endogenous estrogens is much lower in male than in female the xenoestrogenic activity might have higher impact on health risk in males.

In studies using similar approach as the present no correlation between neither CB-153 nor $p, p^{\prime}$-DDE and xenoestrogenicity were found. In contrast to our determination of the more specific impact of serum xenoestrogens on ER transactivation, the other studies used the E-screen MCF-7 cell proliferation as end point $[17,30-32]$. Moreover, we analyzed the xenoestrogenic action in male blood samples whereas the other four studies were focused on female adipose tissues [30-32] and female serum from pregnant and non-pregnant women [17]. These studies determined a higher frequency ( 60-70\%) of subjects with significantly increased estrogenic activity in the nonpolar serum fraction of Spanish and Faroese women. For non-pregnant Danish women the frequency of subjects 


\section{A. XER activity versus $p, p-D D E$}

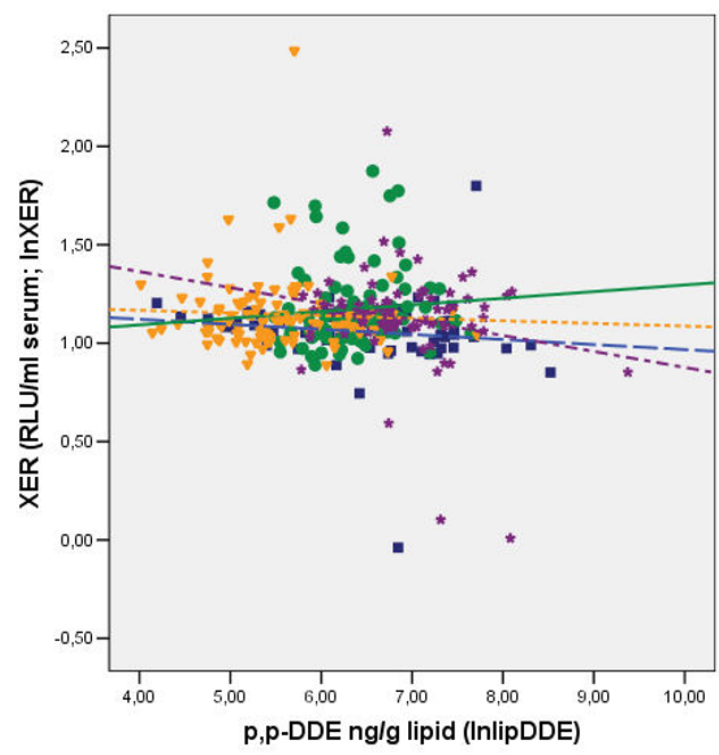

C: XERcomp versus p,p'-DDE

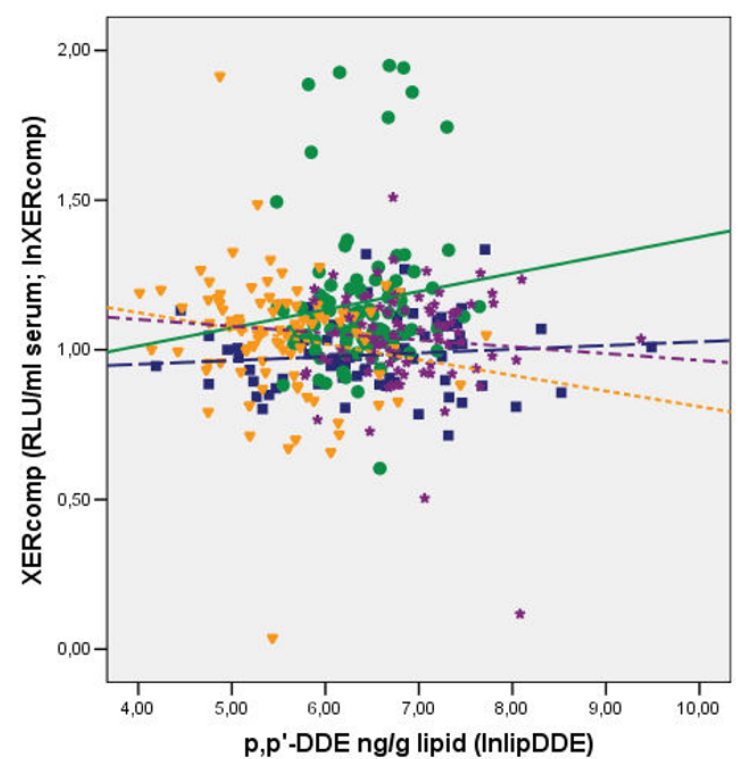

B: XER activity versus PCB-153

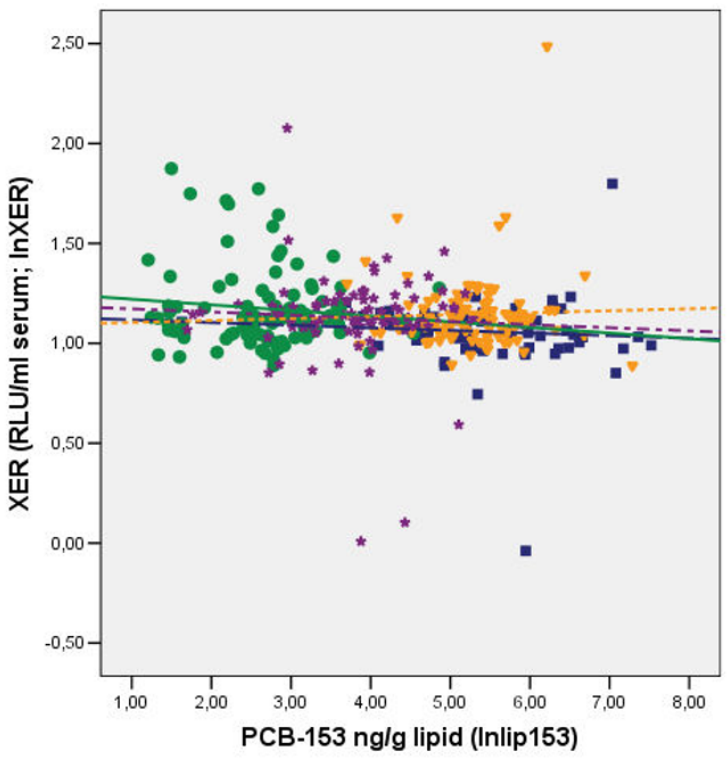

D: XERcomp versus PCB-153

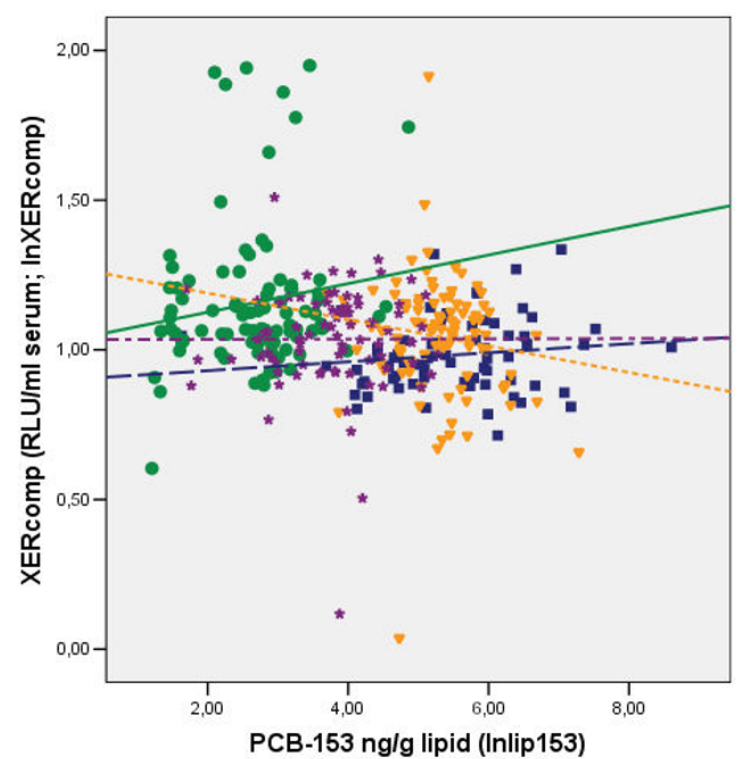

Figure 2

Schematic illustration of xenoestrogenic activities related to the POP markers. Xenoestrogenic (XER) and competitive XER (XERcomp) serum activities related to CB-I53 and $p, p^{\prime}-D D E$ levels for the four country based study groups as a relation between $(A)$ XER and p,p'-DDE, (B) XER and CB-I53, (C) XERcomp and p,p'-DDE, and (d) XERcomp and CB-I53.

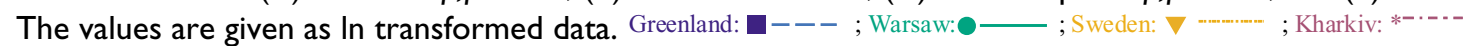

exceeding the background level was $22.7 \%$, similarly to the frequency determined for the European males in the present study. In support to our data it was recently reported that high levels of PCBs in Slovakia male serum samples were associated with a decreased ER mediated activity and increased AhR mediated activity [46]. 
Recently, estrogenicity of adipose tissue extracts including bio-accumulated xenoestrogens was shown associated with higher risk of breast cancer in leaner women [32].

\section{I Conclusions and perspectives}

Across the four study groups no strong consistent correlation between xenoestrogenicity and the two POP proxy markers was found. Thus, the CB-153 and $p, p^{\prime}$-DDE alone are not optimal global POP markers of the integrated xenoestrogenic serum activity. However, between the study groups a clear difference in serum xenoestrogenicity as well as differences in correlation to the CB-153 and $p, p^{\prime}-$ DDE proxy markers was found. Correlations to the POP markers were found for the two study groups at the extreme edge: Inuit's with high sample frequency of antiestrogenicity, and the Warsaw group with higher frequency of samples with estrogenicity. In support to POP biomarker determinations, the present ex vivo biomarker xeno-activity assay may be useful in assessment of geographical surveys for the impact of environmental xenoestrogens, reflecting differences in POP exposure patterns.

On the other hand, exposure assessment based upon measurements of the actual xenoestrogenic serum activity of the isolated SPE-HPLC, F1- POP- fraction may fail to detect effects accomplished 1) by other non-lipophilic compounds in serum, 2) through other receptors or 3) by other mechanisms. More work still needs to be done to fully understand to which extent ex vivo measurements of receptor-transactivation reflect the in vivo situation.

\section{Competing interests}

The author(s) declare that they have no competing interests.

\section{Authors' contributions}

ECB-J drafted the work and was the main responsible for design, performance and data evaluation of the specific project; PHJ, TSR and BSA performed the mechanistic work; CHL performed POP determinations in blood; ME was the main responsible for the statistical work; JPB, AG and LH designed the overall Inuendo project. JPB and GT coordinated the execution of the project and GT had main responsibility for creating the joint database. All authors participated in the design of the study and commented on the final manuscript.

\section{Additional material}

\section{Additional File 1}

Title: Spearman's correlation analyses between xenoestrogenic serum activities and the level of CB-153 and p, $\mathrm{p}^{\prime}-\mathrm{DDE}$. In-transformed and POP lipid adjusted data was used. For definition of XER, XERcomp and $X E R-E E Q$ see legend to Table 2. Statistical significant data is given in bold. ${ }^{1}$ : Spearman's inter-correlation between CB-153 and p, $\mathrm{p}^{\prime}-D D E$, respectively.

Click here for file

[http://www.biomedcentral.com/content/supplementary/1476069X-5-12-S1.pdf]

\section{Acknowledgements}

Thanks to all CMT group members; Inger Sørensen for technical assistance, Tanja Krüger, Manhai Long and Mandana Ghisari for scientific support. A special thanks to Jan K. Ludwicki for coordination of the blood sampling in Warsaw. Also a special thanks to Anna Rignell-Hydbom, Katarzyna Goralczyk, Henning S. Pedersen for taking the blood samples in Sweden, Warswa and Greenland, respectively. Thanks to Héléne Åkesson, Berit Holmskov and Christina Held for performing chemical analyses in a skillful way. This study is part of the Project "INUENDO [33]- Biopersistent organochlorines in diet and human fertility. Epidemiological studies of time to pregnancy and semen quality in Inuit and European populations", supported by The European Commission to the $5^{\text {th }}$ Framework Programme Quality of Life and Management of Living Resources, Key Action 4 on Environment and Health (Contract no. QLK4-CT-200I-00202) and INTAS (contract no 200I-2005). The work has also been funded by the Danish Environmental Protection Agency, the Swedish Research Council and the Swedish Council for Environment, Agricultural Sciences and Spatial Planning.

\section{References}

I. Carpenter DO, Arcaro KF, Bush B, Niemi WD, Pang S, Vakharia DD: Human health and chemical mixtures: an overview. Environ Health Perspect 1998, 106(suppl 6): 1263-1270.

2. Bonefeld-Jorgensen EC: The Human Health Effect Programme in Greenland, a review. Sci Total Environ 2004, 331:215-231.

3. Bonefeld-Jorgensen EC, Ayotte P: Toxicological Properties of POPs and Related Health Effects of Concern for the Arctic Populations (Chapter 6). In AMAP assessment 2002: Human Health in the Arctic Oslo, Norway; 2003:57-74. Volume on-line http:// www.amap.no. Arctic Monitoring and Assessment Programme (AMAP), Oslo, Norway. xiv + 137pP

4. Verrijdt G, Haelens A, Claessens F: Selective DNA recognition by the androgen receptor as a mechanism for hormone-specific regulation of gene expression. Mol Genet Metab 2003, 78:175-185

5. Schwabe JW, Teichmann SA: Nuclear receptors: the evolution of diversity. Sci STKE 2004, 2004:pe4.

6. Bjornstrom L, Sjoberg M: Mechanisms of estrogen receptor signaling: convergence of genomic and nongenomic actions on target genes. Mol Endocrinol 2005, 1 9:833-842.

7. Hess RA: Estrogen in the adult male reproductive tract: a review. Reprod Biol Endocrinol 2003, I:52.

8. Shapiro E, Huang $H$, Masch RJ, McFadden DE, Wu XR, Ostrer $H$ : Immunolocalization of androgen receptor and estrogen receptors alpha and beta in human fetal testis and epididymis. J Urol 2005, 174:1695-1698.

9. Carreau S: Estrogens-male hormones? Folia Histochem Cytobiol 2003, 41: 107-III.

10. Couse JE, Mahato D, Eddy EM, Korach KS: Molecular mechanism of estrogen action in the male: insights from the estrogen receptor null mice. Reprod Fertil Dev 200I, 13:21 I-219.

II. Andersen HR, Vinggaard AM, Rasmussen TH, Gjermandsen IM, Bonefeld-Jorgensen EC: Effects of currently used pesticides in 
assays for estrogenicity, androgenicity, and aromatase activity in vitro. Toxicol Appl Pharmacol 2002, 179: I-12.

12. Long M, Laier P, Vinggaard AM, Andersen HR, Lynggaard J, BonefeldJorgensen EC: Effects of currently used pesticides in the AhRCALUX assay: comparison between the human TVIOIL and the rat H4IIE cell line. Toxicology 2003, 194:77-93.

13. Hofmeister MV, Bonefeld-Jorgensen EC: Effects of the pesticides prochloraz and methiocarb on human estrogen receptor alpha and beta mRNA levels analyzed by on-line RT-PCR. Toxicol In Vitro 2004, 1 8:427-433.

14. Grunfeld HT, Bonefeld-Jorgensen EC: Effect of in vitro estrogenic pesticides on human oestrogen receptor alpha and beta mRNA levels. Toxicol Lett 2004, I 5 I:467-480.

15. Bonefeld-Jorgensen EC, Andersen HR, Rasmussen TH, Vinggaard AM: Effect of highly bioaccumulated polychlorinated biphenyl congeners on estrogen and androgen receptor activity. Toxicology 200I, I 58: | 14|-153.

16. Brouwer A, Longnecker MP, Birnbaum LS, Cogliano J, Kostyniak P, Moore J, Schantz S, Winneke G: Characterization of potential endocrine-related health effects at low- dose levels of exposure to PCBs. Environ Health Perspect 1999, I 07(Suppl 4):639-649.

17. Rasmussen TH, Nielsen F, Andersen HR, Nielsen JB, Weihe P, Grandjean P: Assessment of xenoestrogenic exposure by a biomarker approach: application of the E-Screen bioassay to determine estrogenic response of serum extracts. Environ Health 2003, 2:12

18. Jury HH, Zacharewski TR, Hammond GL: Interaction between human plasma sex hormone-binding globulin and xenobiotic ligands. Journal of Steroid Biochemistry \& Molecular Biology 2000, 75:167-176.

19. Anbalagan J, Kanagaraj P, Srinivasan N, Aruldhas MM, Arunakaran J: Effect of polychlorinated biphenyl, Aroclor 1254 on rat epididymis. Indian J Med Res 2003, I I 8:236-242.

20. Fielden MR, Halgren RG, Tashiro CH, Yeo BR, Chittim B, Chou K Zacharewski TR: Effects of gestational and lactational exposure to Aroclor $\mathbf{2 4 2}$ on sperm quality and in vitro fertility in early adult and middle-aged mice. Reprod Toxicol 200I, 15:28|-292.

21. Kelce WR, Stone CR, Laws SC, Gray LE, Kemppainen JA, Wilson EM: Persistent DDT metabolite p,p'-DDE is a potent androgen receptor antagonist. Nature 1995, 375:581-585.

22. Peterson RE, Theobald HM, Kimmel GL: Developmental and reproductive toxicity of dioxins and related compounds: cross-species comparisons. Crit Rev Toxicol 1993, 23:283-335.

23. Sager DB, Shih-Schroeder W, Girard D: Effect of early postnata exposure to polychlorinated biphenyls (PCBs) on fertility in male rats. Bull Environ Contam Toxicol 1987, 38:946-953.

24. Steinhardt GF: Endocrine disruption and hypospadias. Adv Exp Med Biol 2004, 545:203-2I5.

25. Toft G, Axmon A, Giwercman A, Thulstrup A, Rignell-Hydbom A, Pedersen HS, Ludwicki J, Zvyesday V, Zhinchuk A, Spano M, et al:: Fertility in four regions spanning large contrasts in serum levels of widespread persistent organochlorines: a cross-sectional study. Environ Health 2005, 4:26.

26. Toft G, Hagmar L, Giwercman A, Bonde JP: Epidemiological evidence on reproductive effects of persistent organochlorines in humans. Reprod Toxicol 2004, 19:5-26.

27. Bridges JW, Bridges O: Integrated risk assessment and endocrine disrupters. Toxicology 2004, 205: I - I5.

28. Payne J, Scholze M, Kortenkamp A: Mixtures of four organochlorines enhance human breast cancer cell proliferation. Environ Health Perspect 2001, 109:391-397.

29. Rajapakse N, Silva E, Kortenkamp A: Combining xenoestrogens at levels below individual no-observed-effect concentrations dramatically enhances steroid hormone action. Environ Health Perspect 2002, II 0:917-921

30. Rivas A, Fernandez MF, Cerrillo I, Ibarluzea J, Olea-Serrano MF, Pedraza $V$, Olea N: Human exposure to endocrine disrupters: standardisation of a marker of estrogenic exposure in adipose tissue. Apmis 2001, 109:185-197.

31. Fernandez MF, Rivas A, Olea-Serrano F, Cerrillo I, Molina-Molina JM, Araque P, Martinez-Vidal JL, Olea N: Assessment of total effective xenoestrogen burden in adipose tissue and identification of chemicals responsible for the combined estrogenic effect. Anal Bioanal Chem 2004, 379:163-170.
32. Ibarluzea Jm J, Fernandez MF, Santa-Marina L, Olea-Serrano MF, Rivas AM, Aurrekoetxea JJ, Exposito J, Lorenzo M, Torne P, Villalobos M, et al.: Breast cancer risk and the combined effect of environmental estrogens. Cancer Causes Control 2004, I5:59I-600.

33. http://www.inuendo.dk The European Commission to the 5 th Framework Programme Quality of Life and Management of Living Resources, Key Action 4 on Environment and Health (Contract no. QLK4-CT-200I-00202) and INTAS (contract no 200I-2005). Biopersistent organochlorines in diet and human fertility. Epidemiological studies of time to pregnancy and semen quality in Inuit and European populations.

34. Biological Monitoring: Human Tissue Levels of Environmental Contaminants, Chapter 5. AMAP Assessment Human Health in the Arctic 2003:3I-5I. Volume Publications online http:// www.amap.no (DEFINITIVE_POPS6.pdf). Oslo, Norway: Arctic Monitoring and Assessment Programme (AMAP), Oslo, Norway. $x i v+137 p p$

35. Jonsson BA, Rylander L, Lindh C, Rignell-Hydbom A, Giwercman A, Toft G, Pedersen HS, Ludwicki JK, Goralczyk K, Zvyezday V, et al.: Inter-population variations in concentrations, determinants of and correlations between $2,2^{\prime}, 4,4^{\prime}, 5,5^{\prime}$-hexachlorobiphenyl (CB-I 53) and I, I-dichloro-2,2-bis (p-chlorophenyl)-ethylene (p,p'-DDE): a cross-sectional study of 3161 men and women from Inuit and European populations. Environ Health 2005, 4:27.

36. Rignell-Hydbom A, Rylander L, Giwercman A, Jonsson BA, NilssonEhle P, Hagmar L: Exposure to CB-I53 and p,p'-DDE and male reproductive function. Hum Reprod 2004, 19:2066-2075.

37. Hjelmborg PS, Ghisari M, Bonefeld-Jorgensen EC: SPE-HPLC purification of endocrine disrupting compounds from human serum for assessment of xenoestrogenic activity. Analytical and Bioanalytical Chemistry 2006 in press.

38. Sonnenschein C, Soto AM, Fernandez MF, Olea N, Olea-Serrano MF, Ruiz-Lopez MD: Development of a marker of estrogenic exposure in human serum. Clin Chem 1995, 41 : $1888-1895$.

39. Pons M, Gagne D, Nicolas JC, Mehtali M: A new cellular model of response to estrogens: a bioluminescent test to characterize (anti) estrogen molecules. Biotechniques 1990, 9:450-459.

40. Bonefeld-Jorgensen EC, Grünfeld HT, Gjermandsen IM: Effect of pesticides on estrogen receptor transactivation in vitro: $A$ comparison of stable transfected MVLN and transient transfected MCF-7 cells. Mol Cell Endocrinol 2005, 244:20-30.

4I. Giwercman AR-H Aleksander, Gunnar Toft, Lars Rylander, Lars Hagmar, Lindh C, Henning Pedersen S, Jan Ludwicki K, Maryna Shevets, Valentyna Zvyezday, Marcello Spano, Gian Manicardi Carlo, Davide Bizarro, Eva Bonefeld-Jorgensen, Jens Bonde Peter, INUENDO: Reproductive Hormone Levels in Men Exposed to Persistent Organohalogen Polutants: A Study of Inuit and Three European Cohorts. Environmental Health Perspectives 2006. Submitted the 19 th of December 2005; in revision for publication

42. Svensson BG, Nilsson A, Jonsson E, Schutz A, Akesson B, Hagmar L: Fish consumption and exposure to persistent organochlorine compounds, mercury, selenium and methylamines among Swedish fishermen. Scand J Work Environ Health 1995 , 21:96-105.

43. Rylander L, Hagmar L: Mortality and cancer incidence among women with a high consumption of fatty fish contaminated with persistent organochlorine compounds. Scand J Work Environ Health 1995, 21:419-426.

44. Gregoraszczuk EL, Grochowalski A, Chrzaszcz R, Wegiel M: Congener-specific accumulation of polychlorinated biphenyls in ovarian follicular wall follows repeated exposure to PCB I 26 and PCB I53. Comparison of tissue levels of PCB and biological changes. Chemosphere 2003, 50:48I-488.

45. Connor K, Ramamoorthy K, Moore M, Mustain M, Chen I, Safe S, Zacharewski T, Gillesby B, Joyeux A, Balaguer P: Hydroxylated polychlorinated biphenyls (PCBs) as estrogens and antiestrogens: structure-activity relationships. Toxicol Appl Pharmacol 1997, 145: III-123.

46. Pliskova M, Vondracek J, Canton RF, Nera J, Kocan A, Petrik J, Trnovec T, Sanderson T, van den Berg M, Machala M: Impact of polychlorinated biphenyls contamination on estrogenic activity in human male serum. Environ Health Perspect 2005, I 1 3:1277-1284 
47. Andersen HR, Andersson AM, Arnold SF, Autrup H, Barfoed M, Beresford NA, Bjerregaard P, Christiansen LB, Gissel B, Hummel R, et al.: Comparison of short-term estrogenicity tests for identification of hormone-disrupting chemicals. Environ Health Perspect 1999, 107:89-108.

48. Chen CW, Hurd C, Vorojeikina DP, Arnold SF, Notides AC: Transcriptional activation of the human estrogen receptor by DDT isomers and metabolites in yeast and MCF-7 cells. Biochem Pharmacol 1997, 53: I I6I-1 I72.

49. Grimvall E, Rylander L, Nilsson-Ehle P, Nilsson U, Stromberg U, Hagmar L, Ostman C: Monitoring of polychlorinated biphenyls in human blood plasma: methodological developments and influence of age, lactation, and fish consumption. Arch Environ Contam Toxicol 1997, 32:329-336.

50. Glynn AW, Wolk A, Aune M, Atuma S, Zettermark S, Maehle-Schmid M, Darnerud PO, Becker W, Vessby B, Adami HO: Serum concentrations of organochlorines in men: a search for markers of exposure. Sci Total Environ 2000, 263:197-208.

51. Deutch B, Pedersen HS, Jorgensen EC, Hansen JC: Smoking as a determinant of high organochlorine levels in Greenland. Arch Environ Health 2003, 58:30-36.

52. Gladen BC, Schecter AJ, Papke O, Shkyryak-Nyzhnyk ZA, Hryhorczuk DO, Little RE: Polychlorinated dibenzo-p-dioxins, polychlorinated dibenzofurans, and coplanar polychlorinated biphenyls in breast milk from two cities in Ukraine. J Toxicol Environ Health A 1999, 58: I 19-1 27.

53. Dewailly E, Ayotte P, Brisson J, Dodin S: Breast cancer and organochlorines [letter]. Lancet 1994, 344:1707-1708.

Publish with Bio Med Central and every scientist can read your work free of charge

"BioMed Central will be the most significant development for disseminating the results of biomedical research in our lifetime. "

Sir Paul Nurse, Cancer Research UK

Your research papers will be:

- available free of charge to the entire biomedical community

- peer reviewed and published immediately upon acceptance

- cited in PubMed and archived on PubMed Central

- yours - you keep the copyright

Submit your manuscript here:

http://www.biomedcentral.com/info/publishing_adv.asp
BioMedcentral 